\title{
Intervención estatal y desarrollo económico: a propósito de la revolución en marcha
}

\section{Bernardo Tovar Zambrano Profesor Universidad Nacional de Colombia}

\section{El entusiasmo historiográ- fico por la revolución en marcha}

Se ha convertido en una especie de lugar común en la historiografia colombiana, el referirse a la importancia que para el desarrollo del país conllevó la República liberal (1930-1946) y de modo especial, el período conocido como La Revolución en Marcha, de Alfonso López Pumarejo (1934-1938). En forma relativamente profusa se ha destacado y se continúa reiterando la gran significación que tuvo aquella fase histórica para la modernización del Estado y de la Sociedad Colombiana.

En particular, sobre el primer gobierno de Lopez Pumarejo, como lo observa Alvaro Tirado Mejia, se ha dado un consenso no muy frecuente en la historia de Colombia: "la apreciación que se tiene sobre el periodo es profundamente positiva, como̊ que duranteél el país se modemizó, adecuó los mecanismos estatales a los nuevos tiempos y se vivio un contexto progresista"'.

Ciertamente parececomo si el entusiasmoque la Revolución en Marcha suscitaraen losespíritus progresistas del momento y en las masas populares se prolongase en las visiones históricas sobre el período: el historiador se siente atraído por la descollante figura de López Pumarejo, por la novedad y lucidez de su pensamiento y la fuerza de sus actos, por su gobierno progresista y el apoyo de masas que generó, por las reformas que introdujo y el enconado debate ideológịco que las acompaño, con el ingrediente de una oposición que las atacó con vehemencia, y en fin, por la promoción política de las clases populares que veían en la Revolución en Marcha una oportunidad histórica.

Se trata de un períodocuyaestimación histórica ha crecido con el tiempo. Inclusive, algunos de quienes en su momento se opusieron a la Revolución en Marcha, pasada la conmoción y disipados los últimos temores, comenzarían a comprender la significación del período reformista y a aceptarlo. Por su parte, en la historiografía liberal, sin que cause sorpresa, las imágenes de López y de la Revolución en Marcha se han elevado en algunos casos hasta el punto incluso de situarlos en unas dimensiones no del todo exentas de mitificación o de sobrevaloración histórica. Esta inclinación a la sobrevaloración, desde el punto de vista de la ideología política, no resulta extraña: en este sentido, la ideología tiende a idealizar y mitificar el pasado, y a derivar de esta reelaboración del pasado nutrientes y títulos de legitimidad histórica que sustentan en buena parte la práctica política del presente y su proyección al futuro?

El estilo de gobierno, las ideas que se agitaron, los proyectos progresistas que se buscaban, la movilización de las masas, las esperanzas que surgieron y los logros alcanzados, todo ello dejaba una huella que se percibe como una adquisición histórica que ingresa en la memoria incitando positivamente la mirada del historiador. De este modo, el recuerdo de ese pasado reciente traduce al mismo tiempo un logro y un arraigo históricos que de alguna manera continúan alimentando en términos ideológicos expectativas del presente. Esto parece claro, por ejemplo, si se enfoca desde el punto de vista de las funciones de la política y de los partidos en la construcción del país. En la larga duración que presentan los parti- 
dos tradicionales en Colombia, el rescate de las permanencias así como de los logros y cambios se efectúa en orden a producir una legitimidad histórica articulada siempre a las tareas del presente. En este sentido, el partido político elabora la historia que necesita, reconstruye el pasado según las exigencias del proyecto presente. Desde esta óptica, resulta entonces obvio que se rescate y se subraye lo que se considera el aporte valioso, por ejemplo, de las ideas propugnadas por la Revolución en Marcha, y de la función cumplida por ésta respecto de la modernización del país. Empero,como atrás lo sugeríamos, este proceder historiográfico se halla acechado por el riesgo de caer fácilmente, por lo menos en algunos casos, en el sesgo apologético o en la mitificación histórica.

Ahora bien, entre los muchos aspectos que han sido destacados de la Revolución en Marcha, se subraya de manera especial el que se refiere a la creación del Estado Intervencionista y su eficacia en cuanto a la promoción del desarrollo económico durante el período liberal. Abordar la Revolución en Marcha, a partir de la revisión del aspecto anteriormente señalado, es el propósito del presente artículo.

\section{Una Imagen de la Revolución en Marcha}

Ha sido corriente considerar la Revolución en Marcha como el proceso instaurador de la modernización capitalista de la sociedad y del Estado colombiano. Este proceso fue posible, se afirma, porque con López accedió al control del Estado la burguesía industrial, con su proyecto nacional de industrialización basado en la sustitución de importaciones, el cual constituyó el planteamiento estratégico de la Revolución en Marcha. De este modo, se pusieron en escena los intentos de revolución industrial ${ }^{3}$, de Revolución democráticaburguesa ${ }^{4}$, lo que implicaba la transformación radical del viejo país terrateniente y señorial, en el cual se encontraban rezagos semifeudales c inclusive coloniales. Este orden, al cual correspondía un "Estado agrario", controlado principalmente por los terratenientes ${ }^{5}$ y de modo general no propiamente intervencionista, había entrado en crisis en los años veinte, por lo cual se hacía nece- saria su transformación para dar paso ala República burguesa con su divisa puesta en la industrialización. Para algunos autores, en términos estructurales, se trataba del tránsito de un modelo de desarrollo "hacia afuera", basado en la agroexportación y el mercado mundial, hacia un modelo de desarrollo "hacia adentro", basado en laindustrialización y el mercado interior. De este modo, el cambio político que se produjo en 1930, correspondería, en su significación estructural, a la transición entre aquellos dos modelos: de la República conservadora, agroexportadora, a la República liberal, industrializadora. La realización del objetivo industrializador suponía la modernización de las instituciones, el establecimiento de un Estado interyencionista incentiyador del desarrollo industrial ${ }^{6}$, la adecuación del sector agrario a este desarrollo, la reglamentación de las relaciones entre el capital y el trabajo, en fin, la concepción de una nueva política que adelantara las reformas económicas, sociales y jurídico-institucionales exigidas por el nuevo modelo de desarrollo. Esta política, que apenas se inició con el gobierno de transición de Olaya Herrera, tuvo su máximo despliegue cuando se produjo el ascenso al poder de López Pumarejo y la burguesía industrial?

Dado que el énfasis económico de la Revolución en Marcha estuvo puesto en los objetivos de industrialización, éstos se constituyen en el principal factor explicativo de la política general del gobierno; la Revolución en Marcha resulta entonces comprensible a la luz de los propósitos de industrialización, la política económica y social, lasreformas encaminadas hacia el intervencionismo económico del Estado, la ley 200 , las reformas fiscal y educativa, el tratamiento de la cuestión sindical y salarial, todo ello encuentra su sentido explicativo, en última instancia, en el proyecto de industrialización. En esta óptica Medófilo Medina observa: "La ley 200 resulta explicable sólo a la luz del proyecto de industrialización. Si hasta 1934 el estímulo a la industria se hacía a través del recurso de protección aduanera, ahora se hizo el énfasis en la ampliación del mercado interno. Hay una predeterminación de la política social del gobierno por parte de la política económica, especialmente del proyecto de industrialización. Esta es la verdadera clave para entender la política general del gobierno, el manejo del problema sindical y salarial"s. 
Si la Revolución en Marcha adoptaba como estrategia fundamental el proyecto de industrialización nacional, algunos autores, para demostrar la eficacia práctica de tal política se remiten al campo de las realizaciones: en especial, tienden a concebir el avance industrial del periodo principalmente como resultado de la política estatal, o por lo menos, a asumir que esta políica tuvo una incidenciá notable en la expansión industrial. Se dice que con López concluyó la fase de la industrialización espontánea, iniciada en los años $20, y$ se dio vía a los prospectos de industrialización, a la industrialización como proyecto nacional. En este sentido Gerardo Molina ofrecía que "los estímulos dados por López a los empresarios nacionalistas y eficientes, la filosofía intervencionista adoptada entonces, la reforma tributaria, en la que se establecieron criterios de fomento a la creación de unidades fabriles, todo esto dio resultado y de ese modo aparecieron renglones importantes como los de paffo de lana, acero en varillas, grasas industriales y otros. Al mismo tiempo se ampliaban y modernizaban las cervecerias, los envases de vidrio y los textiles de algodón". Los datos sobre la expansión industrial del periodo son entonces asociados a la eficacia de la política gubernamental. Algunos, de modo más general, hacen depender de dicha política prácticamente todo el avance económico. Así, por ejemplo, Alberto Galindo expresa: "Por el aspecto económico, la primera administración Lópèz aparece claramente como el punto inicial de un extraordinario avance hacia la prosperidad. Todas las dimensiones del país crecieron. En aquellos cuatro años, los recursos nacionales inertes por siglos, se iban poniendoen marcha, bajoel influjo de una intensa y afortunada acción de fomento de los gobernantes $^{m 10}$. Describe la época anterior como de atraso y la compara con la nueva prosperidad que trajo "una producción nacional en aumento, un balance de pagos bien equilibrado, una diplomacia mercantil, y la expansión económica interna suscitada por las reformas liberales"11. Refiriéndose al Estado del período precedente a la República Liberal, manifiesta que "era un testigo impasible de la injusticia, cuando no uno de sus agentes, y un gendarme somnoliento de la pobreza nacional" y agrega: "Del Estado humanista, testigo impasible de la escasez colectiva, a este otro estado intervencionista que creaba los instrumen- tos necesarios para regular la producción y la circulación de riqueza, y para fomentar el consumo, había ciertamente una enorme distancia" ${ }^{\text {"12 }}$.

Para Galindo se trata entonces de un desarrollo económico generalizado, suscitado por las reformas liberales, por la política del nuevo Estado intervencionista incentivador del desarrollo, que contrastaba con la fase anterior de un Estado gendarme, no intervencionista, en un contexto de pobreza nacional.

Loexpuestoanteriormenteserefiere solamente a algunos aspectos de los diversos que se han formulado acerca de la Revolución en Marcha. Empero, el bosquejo realizado nos permite introducir ciertas observaciones, sin pretender, por supuesto, agotar la materia ni tampoco resolver los problemas historiográficos que se plantean en torno a la interpretación de la Revolución en Marcha. Nos limitamos, en consecuencia, a efectuar algunas anotaciones que se suscitan desde el punto de vista de la intervención económica del Estado.

\section{Modernización Capitalista e Intervención del Estado}

Si se enfoca la Revolución en Marcha aislada del contex to histórico, es decir, si se hace abstracción de las tendencias históricas, si se quiere estructurarlas, en las cuales se inscribe, puede llegarse a una apreciación que sobrevalora la significación de dicha "revolución".Porestecamino, para decirlo un poco radicalmente, parecería entonces como si la modernización de la sociedad y del Estado se iniciase con aquel movimiento: tal sería su sentido, en cuanto a la intervención económica del Estado, en particular, se consideraría que tuvo allí también su origen, tantoen el campo de las ideas como de los hechos ${ }^{13}$. Hacia atrás, no se tendría más que el panorama de una sociedad tradicional agroexportadora, sumida en el estancamiento y la pobreza, con un Estado sin funciones ni económicas ni sociales, es decir, un Estado no intervencionista, prácticamentedivorciado de la economía y la sociedad, legitimado por una ideología de no intervencion. Si se dieron hechos en un sentido contrario, es decir, si correspondían a concepciones y actos de intervención y de modernización, no se les concebiría más que 
como excepciones, o se les situaría simplemente en el consabido campo de los "antecedentes": pero el proceso en forma seguiría teniendo como cuna la Revolución en Marcha.

De manera diferente, si ubicamos la Revolución en Marcha en una perspectiva histórica más amplia, no tan coyuntural y aislada, se tiene una concepción bastante distinta a la señalada, o por lo menos notablemente matizada. De este modo, en efecto, la Revolución en Marcha se presenta como una fase, como un momento, ciertamente importante de todo un proceso de modemización capitalista del país, relativamente largo y paulatino, iniciado con anterioridad. La industria, por ejemplo, que constituye un componente central de la modernización capitalista, no surgió en forma súbita, repentina: la industrialización ha sido un proceso lento y evolutivo, que se inició a fines del siglo XIX y se fue desarrollando durante los primeros decenios del siglo $\mathrm{XX}$, viabilizada por un conjunto de condiciones, entre las cuales se destacan las creadas o derivadas de la producción cafetera de exportación. Esta producción, como se sabe, comenzó a tener importancia en los años setenta del siglo pasado, $y$ ha constituído uno de los principales factores que inducían la modernización capitalista. Dado el carácter paulatino y evolutivo de la industrialización, así como las articulaciones entre éste y la economía agroexportadora, se observa que los dos modelos de desarrollo "hacia adentro" y "hacia afuera", no resultan tan radicalmente opuestos ni excluyentes, si no que se establecen unas relaciones de complementariedad, lo cual matiza la etapa de la "transición", descartándose, en consecuencia, la concepción de un salto rápido y súbito entre los dos modelos. Así mismo el entrelazamiento de la economía cafetera con otras actividades, como por ejemplo, el enlace que surge entre comerciantes e industriales, no permite una configuración plena y absoluta de los grupos ni una contraposición antagónica de sus intereses, lo cual, ciertamente, tiene efectos en el comportamiento de los partidos políticos y en las relaciones con el Estado.

Para los primeros decenios del presente siglo, también es notable el crecimiento de la población (que pasó de 4.134.632 habitantes en 1905 a 8.701 .816 en 1938) y del sector urbano, sin que tampoco resulte despreciable el desarrollo de la agricultura ${ }^{14}$

Si bien la expansión y diversificación de las actividades se producía con base en el conjunto de condiciones que se iban gestando en el ámbito de las propias fuerzas económicas, si el despliegue de los factores correspondía al movimiento relativamente autónomo del proceso económico, es factible observar en ello, sin embargo, alguna presencia del Estado encaminada a crear condiciones propicias para ese desarrollo aunque en forma, claro está, bastante limitada. Además del manejo del arancel aduanero en sentido proteccionista, cuya eficacia para el desarrollo industrial se ha cuestionado, pues el arancel obedecía ante todo a un propósito fiscalista (los impuestos de aduana constituían la principal fuente de ingresos del Estado), la intervención económica del Estado era perceptible en dos ámbitos importantes: en las obras de infraestructura (vías de transporte) y en la órbita monetaria. Se ha subrayado la importancia de los ferrocarriles para el desarrollo de la exportación cafetera y también para el surgimiento industrial ${ }^{15}$. Hasta 1904 la red ferroviaria estaba constituída por 565 kilómetros en uso, magnitud que aumentó a $1481 \mathrm{kms}$. en 1922, para elevarse luego a $2.383 \mathrm{kms}$. en 1929. La implantación y expansión de las vías férreas durante toda una fase obedeció a los requerimientos de la economía exportadora; no obstante, hacia los años diez y sobre todo en los años 20 , la construcción de las líneas permitió avanzar ostensiblemente en la articulación del mercado nacional. Dado que el énfasis siempre estuvo puesto en los ferrocarriles, el adelanto en la construcción de carreteras fue precario hasta 1930: hacia este año, empero, existían 5.473 kilómetros. A partir de los años treinta el énfasis se trasladará de los ferrocarriles a las carreteras, las cuales constituirian la nueva base infraestructural para las articulaciones de mercado.

En cuanto a la cuestión monetaria, la cual no ha recibido la atención que se merece, la injerencia del Estado era evidente y significativa. Ya desde 1880 con la fundación del Banco Nacional, seguida luego de la implantación del papel moneda de curso forzoso el Estado adquirió prácticamente el control de la esfera monetaria. Desde entonces, siendo un dominio del Estado, la cuestión monetaria revistió múltiples facetas problemáticas, cuyos efectos para el desarrollo económico están 


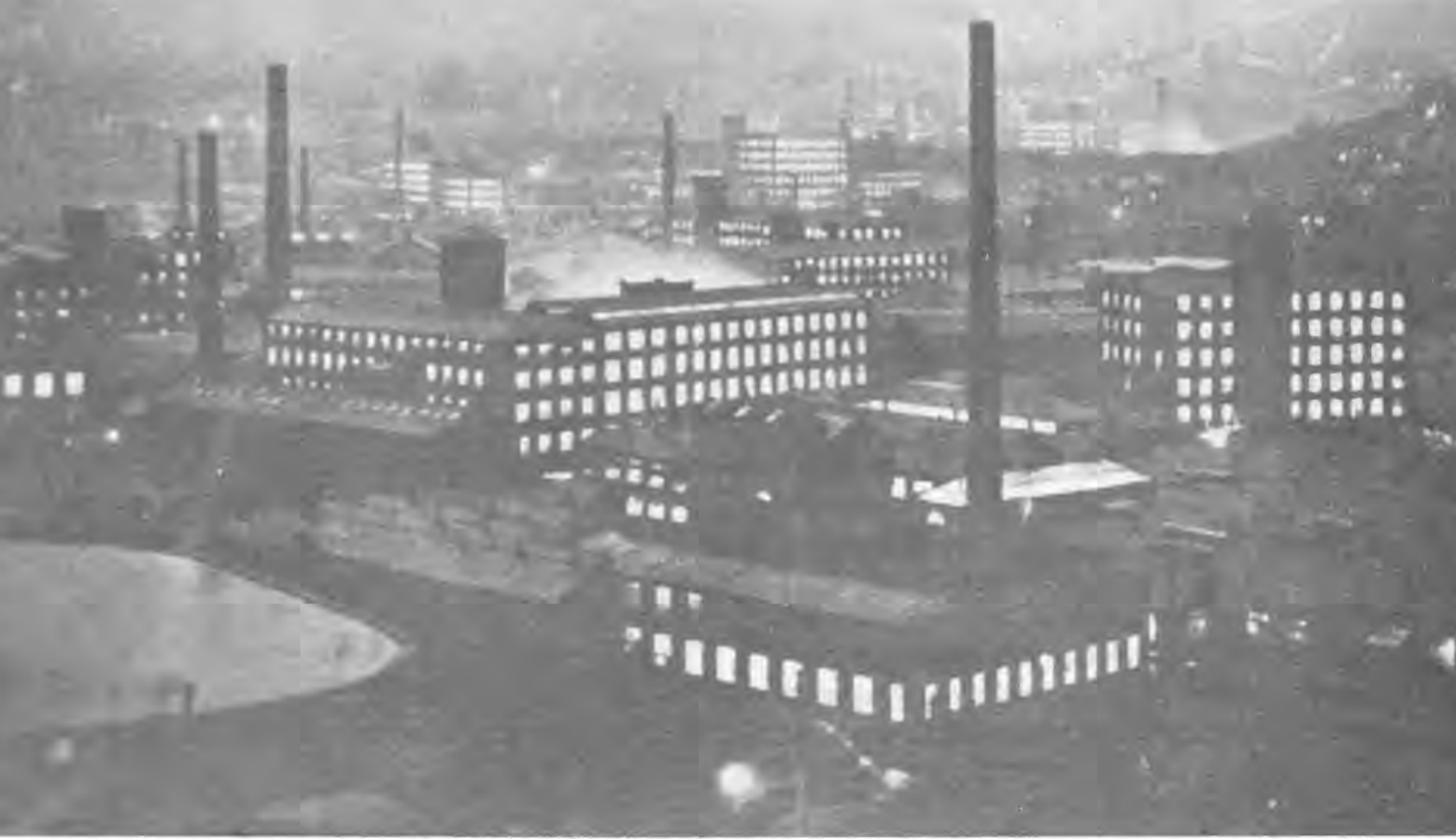

aún por estudiarse. A partir de los problemas que suscitó el establecimiento del papél moneda de curso forzoso, con las gigantescas omisiones que se hicieron para financiar la guerra de los Mil Días, pasando por las medidas correctivas del Quinquenio de Reyes y el drama monetario que se agudizó durante la coyuntura de la Primera Guerra Mundial, la organización del régimen monetario y financiero constituyó siempre un grave problema, èl cual sólo vino a resolverse con la Reforma Financiera de 1923, inspirada en la Primera Misión Kemmerer y efectuada bajo la administración de Pedro Nel Ospina. Con esta reforma, y en especial con la Fundación del Banco de la República, el Estado le dio una estructura al manejo de los asuntos monetarios y financieros, y adquirió importantes instrumentos de intervención que le permitieron tanto acceder a los grandes empréstitos de los años 20, como enfrentar en parte los efectos de la crisis de los años 30.

Dentro de la dimensión de la intervención económica es necesario observar los ingresos y gastos del Estado. En cuanto a los ingresos, éstos dependían en lo fundamental de los impuestos a la importación de mercancías, renta insegura, inelástica y regresiva, sometida siempre a las fluctuaciones del comercio exterior. Durante la crisis ocasionada por la Primera Guerra Mundial se criticaba el impuesto de aduanas el cual -se argumentaba- por su carácter inflexible, su falta de elasticidad y su carencia de equidad, no podía constituír la base tributaria para el ejercicio de las funciones modernas que asumía el Estado en los ámbitos de la economía y de la sociedad ${ }^{16}$. Dicha base -se decía- debía constituírla el impuesto sobre la renta, el cual efectivamente se estableció, con muchas fallas y limitaciones, en 1918. Sin embargo, el impuesto a la renta no dio los rendi mientos que se esperaban, pese a las reformas que se le introdujeron en 1927 y 1931. Sólo a partir de la Reforma Tributaria de 1935, el impuesto comenzó a adquirir una significativa importancia, hasta llegar a convertirse en la espina dorsal del sistema tributario. La estrechez general de los ingresos ordinarios del Estado imponía así mismo una reducida capacidad de gasto, el cual se orientaba predominantemente hacia los gastos de administración y funcionamiento. Dada esta condición, siempre se consideró que para adelantar las obras de progreso, como las vías de comunicación, se debía apelar a los ingresos extraordinarios, a los empréstitos externos. Sin embargo, con el recurso del papel moneda, la centralización fiscal y el aumento de los impuestos de aduana, se incrementaron los gastos de inversión y fomento entre 1886 y 1890 , pudiéndose adelantar algunas obras públicas. Esto se interrumpió con la crisis fiscal subsiguiente y sobre todo con las guerras de 1895 
y de 1899-1902, que determinaron una orientación del gasto público hacia los gastos militares. Nuevamente, a partir de la reorganización fiscal del Quinquenio se incrementaron los ingresos del Estado, lográndose de igual modo un avance en el fomento económico y las obras públicas, hasta la crisis de la Primera Guerra Mundial, la cual, después de un breve auge de post guerra, empató con la crisis de 1920-21. La situación cambió radicalmente durante el auge de los años 20 , con el aumento de los ingresos ordinarios, y de modo especial con el enorme incremento de los ingresos extraordinarios, ocasionado por la afluencia de los grandes empréstitos externos, que dotaron al Estado de una capacidad de gasto nunca antes conocida. Ello motivó una expansión sin precedentes de los gastos de inversión, lo que se tradujo, pese al desorden, en un avance apreciable de diversas obras públicas, especialmente de ferrocarriles $^{\text {t7 }}$.

También en el campo social el Estado comenzó a intervenir, aunque en una forma mucho más tenue que en el económico. Hasta la iniciación de los años 20 solamente se había impartido alguna legislación sobre jubilaciones de empleados públicos (1905), de magistrados y jueces y maestros de escuelas primarias oficiales (1907), sobre accidentes de trabajo (1915) y sobre habitaciones para obreros (1918). En 1919 y 1920 se expidieron las leyes sobre huelgas, y en 1924 se organizó la Oficina General del Trabajo, encargada de atender la cuestión social y laboral. Otras leyes expedidas en los años 20 se refieren al seguro colectivo obligatorio (1921-23), al reglamento de trabajo e higiene en las empresas (1925) y al descanso dominical (1926). En general, la intervención del Estado en la cuestión social agraria era todavía más precaria. Acerca del trabajador campesino existían únicamente las leyes sobre colonización que le otorgaban un derecho al colono por el cultivo de terrenos baldíos y las disposiciones sobre el reconocimiento de mejoras.

Si de un lado, buena parte de aquella legislación social no pasaba de la formulación escrita, de otra, la intervención del Estado en los conflictos suscitados asumía con reiterada frecuencia la forma elemental de la represión violenta de los trabajadores, en favor de los empresarios y propietarios. Esta forma de actuación cambiaría sustan- cialmente con los gobiemos liberales de los affos 30 .

Desde el punto de vista de los gastos sociales se demuestra así mismo la baja incidencia del Estado en la satisfacción de las necesidades sociales: durante los años 20, la magnitud de estos gastos fue irrisoria. Aunque la situación varió un poco entre 1934-38, puede observarse, sin embargo, que dichos gastos permanecieron relativamente constantes durante el período de la República Liberal ${ }^{\text {is. }}$

Enfocada como un proceso, la intervención del Estado, dentro de sus obvias limitaciones y desigualdades, a la vez que guardaba relaciones de implicación y concomitancia con el desarrollo básico de la modernización económica, se incrementaba o se afirmaba en determinados momentos coyunturales. Esto comenzó a ser explícito durante el período de la Regeneración, cuya política se orientó hacia el fortalecimiento institucional y económico del Estado Central, asignándole las funciones de garantizar la paz y el orden y de promover el desarrollo económico. Los conflictos político-militares de fines de siglo ocluyeron la acción del Estado en orden a la promoción del desarrollo, sin embargo, con el Quinquenio de Reyes se produjo de nuevo un fortalecimiento del Estado que le permitió desplegar una actividad económica significativa. Refuriéndose a este período, Darío Mesa sugiere que se trata precisamente de los comienzos en la construcción del Estado nacional modemo ${ }^{19}$.

En este momento se destaca la acción del Estado tanto para enfrentar las dramáticas consecuencias de la guerra de los Mil Días como para estimular el desarrollo. De igual manera, el Estado pondría en juego una política intervencionista y adquiriría nuevos instrumentos de manejo económico en otros momentos críticos, tales como los presentados durante la Primera Guerra Mundial, la crisis de 1920-21 y sobre todo, durante la gran crisis de los años 30 . En estas coyunturas el Estado desplegaba una política anticrisis que traía como consecuencia un fortalecimiento de su intervención económica.

Con la breve exposición anterior hemos pretendido señalar el hecho de que durante las primeras décadas del siglo XX tomaba cuerpo el proceso de modernización capitalista del país, 
seguido, así mismo, de una relativa presencia económica del Estado. Ya para los años 30, modernización e intervención estatal constituían tendencias que se habían perfilado en el transcurso de una historia precedente. En esta historia, el Estado en el espacio doble y circunscrito de su intervención, desarrollaba una política que si bien correspondía a sus funciones de garantizar la articulación de la economía al mercado mundial en cuanto economía agro-exportadora, contribuía a crear, al mismo tiempo, algunas condiciones básicas para el desarrollo de la economía interior. La naturaleza de la intervención y su dimensión circunscrita, no permitiría concluír que se trataba propiamente de un estado agrario, no intervencionista. Tampocoes plausible concebir que se trataba de un Estado controlado e instrumentalizado por los terratenientes o hacendados, pues de este modo, como lo sugiere Hugo López, resulta inexplicable no sólo la ley de emergencia (1926-27) por medio de la cual se obvió la importación de productos agrícolas, medida que lesionaba a los agricultores nacionales, sino también la política económica de los gobiemos conservadores de los años 20 , que obedecía a propósitos más generales que el interés de los terratenientes ${ }^{20}$. En sentido general, la intervención del Estado se ejercía en función de la acumulación de capital en los sectores privados de la economía, los cuales precisamente le determinaban tanto la orientación como las posibilidades y límites a la intervención; ese carácter de la intervención predominaba ostensiblemente sobre las funciones sociales del Estado, las cuales eran relegadas a planos secundarios, recibiendo apenas una precaria atención.

Ahora bien, como veremos enseguida, aquel proceso de intervención iba acompañado de una ideología que de alguna manera lo expresaba y lo sustentaba.

\section{La Ideología de la Intervención Estatal}

La ideología intervencionista presenta una doble dimensión: de un lado se la encuentra, por decirlo así, en "estado práctico", directamente asociada o implicada en el ejercicio mismo de la intervención; de otro lado, se la halla en estado de formulación explícita, en un discurso que en cier- ta forma apunta hacia el plano teórico. La historia de esta ideología es bastante compleja, y aquí nos limitamos solamente a sefialar el enunciado de algunos postulados intervencionistas, sin entrar a desarrollar toda la complejidad que llevan consigo.

En la primera dimensión se encuentra el aspecto pragmático de la ideología intervencionista que se despliega en la ejecución misma de las actividades estatales. A la representación de este nivel corresponde, ante todo, el "discurso del Estado", constituído por los textos oficiales, tales como las constituciones, leyes, informes y memorias de los ministerios de Industria, del Tesoro, de Hacienda, de Obras Públicas, etc. En la segunda dimensión se encuentran los postulados intervencionistas formulados y sustentados por un conjunto de pensadores, quienes por lo general combinaban las tareas políticas o de gobiemo con una actividad intelectual.

El planteamiento del Estado intervencionista siempre estuvo asociado a las condiciones concretas por las que transitaba el país. De este modo, estuvo presente en la empresa política de la Regeneración y en el pensamiento de Núnez. En su crítica al liberalismo radical y al Estado federal, Núñez planteaba la necesidad del Estado central fuerte y le otorgaba a éste ciertas funciones intervèncionistas en lo económico y social. En su discurso de posesión presidencial en 1880 exponía la necesidad de realizar un vasto plan de medidas destinadas a promover el desenvolvimiento de la producción doméstica"21. Ese plan entrañaba la orientación del Estado hacia el desarrollo económico, el cual debía efectuarse con base en la protección de las industrias, la construcción de ferrocarriles y la implantación de un nuevo sistema monetario y de dirección de la política bancaria $^{22}$. En relación con este último punto Núñez sostuvo la teoría estatal del dinero, tema que será motivo de polémica a fines del siglo XIX y comienzos del XX, debateen el cual se planteará y discutirá la intervención económica del Estado. Núñez, además, le otorgaba un carácter social a la intervención del siguiente modo: "No se preconiza la intervención inmoderada o inoportuna delEstado en loque llaman problema social; pero sí la que sea necesaria para resguardar el interes común contra abusos de los poderosos ${ }^{23}$. En su práctica de gobiemo, comose sabe, Núfez ejecutó algunas medidas intervencionistas de importante significación en el campo económico. 
Las ideas intervencionistas de la Regeneración, de alguna manera, se plasmaron en la constitución de 1886. Como lo han observado algunos autores ${ }^{24}$ el principio intervencionista se contenía en los siguientes artículos: en el artículo 76 que establecía como atribuciones del Congreso fijar la ley, peso, típo y denominación de la moneda y arreglar el sistema de pesos y medidas; organizar el crédito público; decretar las obras públicas que hayan de emprenderse, fomentar las empresas útiles y benéficas dignas de estímulo y apoyo; en el artículo 120 que fijaba como atribuciones del presidente reglamentar, dirigir e inspeccionar la instrucción pública nacional; celebrar contratos administrativos para la prestación de servicios y ejecución de obras públicas; organizar el Banco Nacional y ejercer la inspección necesaria sobre los Bancos de emisión y demás establecimientos de crédito; ejercer el derecho de inspección y vigilancia sobre instituciones de utilidad común; en el artículo 185 que faculta a las asambleas departamentales para dirigir y fomentar la instrucción primaria, la beneficencia, las industrias establecidas y la introducción de nuevas, la inmigra- ción, la importación de capitales extranjeros; la colonización de tierras, la apertura de caminos, canales navegables y vías férreas, la explotación de bosques, la canalización de ríos y cuanto se refiera a los intereses seccionales y al adelantamiento interno ${ }^{25}$.

En el campo de las concepciones intervencionistas se destaca también Miguel Antonio Caro. En la concepción de Caro el Estado adquiría un amplio campo de acción que iba desde el moral hasta el económico ${ }^{26}$. En este último aspecto sobresalen sus planteamientos acerca de las funciones monetarias del Estado, formuladas en el debate sobre el Banco Nacional y el papel moneda de curso forzoso que Caro defendía. Sostenía que las cuestiones sobre moneda no podían tratarse "exclusivamente en el terreno económico, con independencia del jurídico, La moneda es una creación de las naciones, y el Estado tiene por derecho natural el poder fijarla, como precio común de las cosas"27. El privilegio de la emisión de moneda, era, en consecuencia, una prerrogativa del Estado.

Al entrar el siglo XX en la perspectiva de la intervención, dos personajes descuellan: uno, en la formulación de los principios intervencionistas; el otro en la pragmática de la intervención. Se trata de Rafael Uribe y Rafael Reyes. Uribe expresó su concepción de la intervención estatal en su célebre conferencia de 1904 sobre "el socialismo de Estado". En Uribe el concepto de socialismo de Estado designa precisamente el intervencionismo de Estado. "No soy partidario -decía- del socialismo de abajo para arriba que niega la propiedad, ataca el capital, denigra la religión, procura subvertir el régimen legal y degenera, con lamentable frecuencia, en la propaganda por el hecho, pero declaro profesar el socialismo de arriba para abajo, por la amplitud de las funciones del Estado" 28 , Uribe proponía una acción global del Estado sobre la economía y la sociedad para impulsar el desarrollo: "El Estado -decía- no es órgano de simple conservación sino también de progreso; su fin exclusivo no es mantener el orden, la paz, la obediencia: esa es apenas una condición previa, indispensable para lograr más altos fines. Además de cuidar de lo que encuentra hecho y oponerse a todo deterioro, debe procurar el adelanto (...) impulsar y promover tan podero- 
samente como pueda la progresidad del país"zo. Según Uribe eran funciones del Estado la ejecución de las obras costosas, de utilidad común y largo aliento; la legislación para el mejoramiento sociál; la protección de los intereses que no pueden defenderse por sí solos; el amparo de los débiles frente a los poderosos; y la mediación entre las clases encontradas. El Estado debía asi mismo proteger las industrias nacionales y la participación de los obreros en las ganancias de la industria; organizar el ahorro, fundar bancos hipotecarios para impulsar la agricultura; desarrollar el seguro y los sistemas cooperativos; controlar los precios de los víveres; fijar los contratos de arrendamiento para convertir en propietarios a "los siervos de la gleba"; crear el Ministerio de Agricultura; fundar colonias agrícolas; ocuparse de la salud, la educación, la recreación, la defensa del salario, etc. Era evidente que Uribe al mismo tiempo que preconizaba la intervención económica del Estado le otorgaba un ostensible contenido social. Con Uribe el Partido Liberal comenzó a abandonar sus viejas concepciones de Estado gendarme, su postulado de Laissez Faire, Laissez Passer, para avanzar en la concepción del Estado intervencionista.

Rafael Reyes fue ante todo un hombre de una ideología pragmática. Consideraba que la autoridad y el orden debían contribuír al progreso económico y a ello propendió como gobernante. "Durante el gobierno de Rafael Reyes -observa Humberto Vélez- el Estado asumió un papel tan activo en el proceso económico como, quizás, no había sucedido con ninguno de los gobiemos anteriores" ${ }^{30}$. Como es conocido, además de las medidas monetarias, la reorganización fiscal y el manejo de la deuda pública, su política buscó estimular el desarrollo de la agricultura de exportación, la creación de algunas industrias y la expansión de los ferrocarriles.

En los años subsiguientes al Quinquenio y sobre todo durante la crítica coyuntura de la Primera Guerra Mundial, el tema de la intervención del Estado se planteó en relación con toda una problemática económica que hacía referencia al desarrollo de la agricultura, de las exportaciones $\mathrm{y}$ de la industria; al régimen monetario, $\mathrm{y}$ financiero; a la cuestión fiscal y el desarrollo de las vías de comunicación.
En los gremios económicos se tenta uns ciara conciencia de que el Estado debía, además de estimular las exportaciones, contribuir al desarrollo de la agricultura y de la industria. Así lo demuestran, por ejemplo, las exigencias que se hicieron al Estado desde el Primer Congreso Agrario de $1911^{31}$, hasta los Primeros Congresos de Cámaras de Comercio y de Mejoras Nacionales, realizados en 1917" . Si bien esas exigencias eran diversas, según los intereses de cada gremio, tendían a confluir en dos aspectos principales: el desarrollo de las vías de comunicación y la solución del problema monetario. En relación con este último, se suscitó un interesante debate, en el centro del cual estaba la cuestión sobre las funciones del Estado con respecto al dinero: de un lado, había quienes sostenían el principio de la libertad de emisión; del otro, había quienes consideraban que la emisión era un privilegio exclusivo del Estado; terceras posiciones aceptaban que la emisión era un derecho del Estado, pero argumentaban que el Estado no debía practicar directamente ese derecho, sino delegarlo; concluían en la necesidad de organizar un banco de emisión.

En 1918, con el objeto de sustentar la creación del impuesto sobre la renta, Esteban Jaramillo formula una clara concepción del Estado intervencionista. Jaramillo planteaba la reforma tributaria no sólo como una respuesta a los problemas inmediatos de la crisis fiscal, sino, ante todo, como la condición necesaria para el desempeno de las funciones modernas del Estado. Según Jaramillo, la característica esencial del Estado contemporáneo consistía en la creciente ampliación de su esfera de acción en los diversos ámbitos de la sociedad. "Legislación -decía- orden interior, administración de justicia, comunicaciones dentro y fuera del pais, relaciones exteriores, hacienda pública, guerra, marina, instrucción pública, manejo de fondos nacionales, comercio, agricultura, trabajo, obras públicas, higiene, beneficencia, en una palabra, las principales manifestaciones de la vida moderna, corresponderá a otros tantos órganos de la acción vigilante, dirección, protección y fomento del gobiemo" $x$. Las concepciones intervencionistas serían desarrolladas por Jaramillo en sus escritos posteriores, y se enriquecerían, inclusive, con una notable 
experiencia administrativa. Jaramillo tendría una figuración importante en los años 20, y de modo especial, en la política anticrisis a comienzos de los años treinta.

Para resumir, hacia los años treinta, mediando la experiencia intervencionista de la década del 20 , existía ya conformada una cierta tradición intervencionista tanto en el campo de los hechos como de las ideas. Los partidos políticos contemplaban en sus programas la intervención del Estado. El Partido Liberal, por ejemplo, había abandonado sus tesis tradicionales de Estado gendarme y se había enrutado por la senda de la intervención, cambio que fue acompañado de prolongadas polémicas sobre el intervencionismo estatal y el libre juego de los factores individuales. En ese debate, personajes como Alejandro López y Luis Eduardo Nieto Caballero ${ }^{34}$ sustentaban las concepciones intervencionistas. Con la crisis de los años 30 , el intervencionismo iría a recibir un amplio reforzamiento, tanto en el nivel ideológico como en el ejercicio práctico, a lo cual contribuiría significativamente la política y las reformas de la Revolución en Marcha.

\section{Amplitud y Consolidación de la Intervención Estatal}

Como atrás lo indicábamos, durante la crisis de los años treinta la intervención del Estado recibió un nuevo impulso, fortificándose y ampliando su radio de acción. Esto se produjo como reacción del Estado para enfrentar los efectos de la crisis, durante la administración de Olaya Herrera. Las principales medidas intervencionistas no tradicionales adoptadas para combatir la crisis fueron las siguientes: el establecimiento del embargo de oro, o sea, la suspensión del libre comercio de este metal; el establecimiento del control de los cambios internacionales y de traslado de los fondos al exterior; la supresión de la convertibilidad del billete y del patrón oro; la derogación de la "ley de emergencia", el establecimiento de un nuevo arancel proteccionista y la restricción a las importaciones, todo lo cual favorecía a la agricultura y a la industria; la modificación a la política del Banco de la República que permitió abrir el crédito al gobiemo; el aumento del gasto público posibilitado principalmente por las operaciones de crédito con el Banco de la República y el empréstito patriótico a raíz del conflicto con el Perú, lo cual tendió a dinamizar la economía; el arreglo del problema de los deudores privados que evitó su ruina; la devaluación del peso que trajo efectos estimulantes para la exportación cafetera y finalmente la moratoria en el pago de la deuda externa que se tomó tardíamente. A esto habría que agregar la función cumplida por las nuevas instituciones creadas durante la crisis: la Caja Agraria y el Banco Central Hipotecario. También se crearon el Consejo de la Economía Nacional y la Oficina de Control de Cambios, la cual, además de controlar el flujo de dinero al exterior, podía incidir en el aumento de la oferta monetaria a través de la devaluación del peso o de la preparación de un presupuesto deficitario ${ }^{35}$.

Aquellas medidas le permitieron al Estado amortiguar los efectos de la crisis no sólo para el Estado mismo, sino también para los diversos gremios y sectores económicos del país. Tales medidas combinadas con una reposición temporal de los precios del café, posibilitaron iniciar la recuperación económica, la cual ya se enunciaba en 1933. Al mismo tiempo, la crisis había contribuído a expandir y fortificar la intervención del Estado: de la crisis brotaba un Estado con mayores funciones económicas. De igual modo, en el ámbito social el Estado ampliaba su injerencia, motivada principalmente por los conflictos sociales, agrarios y urbanos. Respondiendo a la cuestión social, la administración Olaya expidió un conjunto de leyes, entre las cuales se destacaban las siguientes: la ley 83 de 1931 , que reconoció el derecho a la sindicalización y reglamentó el ejercicio de la huelga; la ley 105 de 1933, que estableció la inembargabilidad parcial de los salarios; la ley 10 de 1934 que creó las prestaciones sociales de vacaciones, cesantías por despido injusto y auxilio por enfermedad, para los trabajadores del sector privado; y el decreto 895 de 1934 que limitó a 8 horas la jornada laboral. Además, se gestó la ley de tierras que cristalizaría en el gobierno de López Pumarejo, y se cambió la actitud del Estado frente al tratamiento y resolución de los conflictos, lo cual contrastaba con la actitud de los gobiernos conservadores del período anterior. 
Mediando la experiencia intervencionista del Estado durante la crisis, se había afianzado con mayor fuerza el postulado del intervencionismo estatal. Al respecto manifestaba Esteban Jaramillo: 'Ta tendencia intervencionista del Estado es ya un hecho indiscutible, que se ha impuesto en el mundo, al mismo tiempo que la convicción de que el Estado tiene una misión social qué cumplir. Yo creo que el régimen capitalista continuará, pero con modificaciones que los tiempos mismos irán imponiendo como ahora se han impuesto... Creo muy difícil e inconveniente después de iniciada esa tendencia, abandonarla. No sé si ella determine un nuevo régimen económico, pero lo cierto es que se han demostrado los beneficios del control y la vigilancia del Estado sobre muchos campos en que antes no se ejercía"mo

Con el advenimiento de la Revolución en Marcha, el intervencionismo de Estado recibió un nuevo impulso. Este se situó, principalmente, en el orden de tres dimensiones: en la conformación de la base fiscal que exigía el Estado intervencionis. ta (Reforma Tributaria); en la determinación de los fundamentos constitucionales para el ejercicio de la intervención (Reforma Constitucional) y finalmente, en el orden práctico de la política económica y social, y la ampliación de la intervención hacia nuevos ámbitos (ley de Tierras, Reforma Educativa).

Si el Estado había asumido funciones intervencionistas y las continuaba ampliando, era evidente que ello implicaba un incremento de sus gastos, lo cual chocaba con la estrechez y fragilidad del sistema tradicional de ingresos estatales. Resultaba claro entonces que el Estado no podía continuar dependiendo en lo fundamental de los impuestos de aduana. Tampoco el Estado podía fincar sus expectativas financieras para impulsar el desarrollo exclusivamente en los empréstitos extemos, ni continuar indefinidamente con la práctica iniciada en 1931, de satisfacer sus necesidades financieras con empréstitos suministrados por el Banco emisor, pues ello estaba ligado a los problemas monetarios de la inflación.

La contradicción que se planteaba entonces entre los requerimientos financieros del Estado y la rigidez del régimen tributario vigente, imponía la necesidad de la Reforma Tributaria, la cual bus. caba instalar la tributación directa, personal y progresiva en la base del Estado intervencionista.
Además de este objetivo que pretendía captar recursos afectando a las grandes fortunas, poniendo a tributar a las personas de altos ingresos en una proporción mayor a las de bajos ingresos, la Reforma Tributaria era concebida como un instrumento de política económica y social por medio del cual el Estado podía incidir en la distribución de la riqueza, en la corrección de las desigualdades sociales, en la orientación y reforma de la organización económica nacional". Después de una fuerte oposición de los gremios económicos, la Reforma Tributaria se concretó en la ley 78 de 1935 , siendo complementada con otras disposiciones en 1936. Dicha reforma elevó sustancialmente la tasa para las tarifas altas, haciendo pasar del $8 \%$ al $17 \%$ la tarifa mayor, modific 6 las disposiciones sobre exenciones y deducciones, terminando con los abusos que permitian la evaporación de la renta gravable, incorponó el criterio de que la renta consolidada por la posesión de un capital debe gravarse más que la que se origina en el simple trabajo, para lo cual se creo el impuesto adicional sobre el valor del patrimonio; se estableció asi mismo el impuesto sobre el exceso de utilidades, como adicional al de renta; estableció procedimientos y normas para evitar los fraudes y las evasiones; finalmente se modificó la constitución nacional para permitir la inspección de documentos privados con fines tributarios. $\mathrm{La}$ Reforma Tributaria fue eficaz: si para 1935 el impuesto a la renta representaba el $7.6 \%$ de los ingresos ordinarios del Estado, para el afio siguiente dicho impuesto, adicionado con los de patrimonio y exceso de utilidades, representaba el $12.4 \%$ y para 1940 el $27.7 \%$ \%.

Con la Reforma Tributaria, el Estado adquiría una base intema de ingresos más elástica y consistente, un instrumento de política económica y social, lo cual le permitiría ir ejecutando y ampliando sus funciones económicas. En este sentido, por ejemplo, uno de los efectos de la Reforma Tributaria, como lo han puesto de manifiesto José Antonio Ocampo y Santiago Montenegro, fue el de posibilitar la liberación de la política arancelaria de la secular determinación fiscalista que le imponía el Estado, para que de este modo entrara a desempeffar plenamente su función reguladora del comercio exterior ${ }^{39}$.

Como es bien conocido, la Reforma Consti- 
tucional de 1936 consagró el intervencionismo estatal. Mucho se ha discutido sobre la interpretación de las fórmulas consignadas en la constitución, y aquí, obviamente, no vamos a entrar en esa discusión. Bástenos señalar algunos aspectos: en su conjunto, la Reforma Constitucional disponía la intervención del Estado en un amplio radio que abarcaba esferas de la economía y de la sociedad. Disponia que "el Estado puede intervenir por medio de leyes en la explotación de industrias o empresas públicas o privadas, con el fin de racionalizar la producción, distribución y consumo de las riquezas, o de dar al trabajador la justa protección a que tiene derecho"; garantizaba la propiedad privada, pero establecía que "la propicdad es una función social que implica obligaciones"; le otorgaba al Estado "la suprema inspección y vigilancia de los institutos docentes públicos y privados". Establecía que la asistencia pública es función del Estado yue cl trabajo es una obligación social y gozará de la especial protección del Estado y garantizaba el derecho de huelga; reproducía así mismo disposiciones intervencionistas impartidas en Actos Legislativos de años anteriores, con los que se referían a la restricción de la producción y consumo de licores y bebidas fermentadas (Acto Legislativo No. I de 1921) y a la revisión y fiscalización de las tarifas y reglamentos de las empresas de transporte y demás servicios públicos (Acto Legislativo No. 1 de 1918) 40 $^{40}$.

Descle el punto de vista de la formalidad jurídica, el Estado adquiría, además de la proyección económica, "deberes sociales", funciones en la cuestión social. Empero, esto fue visto por los opositores a la reforma, como el camino abierto para la omnipotencia del Estado, la abolición de la propiedad privada y el establecimiento del comunismo o del socialismo, pese a que los más brillantes promotores de Ia Reforma cran verdaderamente explícitos en demostrar que no contenía nada de ello. Como lo han expresado algunos autores, la Reforma buscaba la modemización del Estado en orden a sus funciones cconómicas y sociales, según los requerimientos que planteaba el modelo de desarrollo capitalista del país. Refiriéndose al carácter de la Reforma, Molina manifiesta que lo que hizo fue ponernos en presencia de un momento significativo del constitucionalismo social, que es una novedad del siglo
$X X$, pero que la mencionada Reforma en el transcurso posterior no ha tenido desarrollos apreciables, "por lo cual conserva más bien el carácter de una declaración de principios"4t.

Basándose formalmente en el canon constitucional de 1936, acerca de la función social de la propiedad, el Estado, en dicho año, buscó intervenir en la cuestión agraria, para lo cual expidió la ley 200. Uno de los aspectos centrales de la ley era el de establecer la obligatoriedad de la explotación económica de los predios y de que la explotación da derecho al dominio; de este modo se asociaban trabajo y propiedad. Sin embargo, la ley agraria no buscaba una Reforma Agraria encaminada a la democratización de la tierra, ni a una redistribución para la conformación de pequeños propietarios, ni tampoco desmontar la gran propiedad territorial. Lo que pretendía la ley era racionalizar la explotación de la tierra de conformidad con las exigencias del desarrollo capitalista, de estimular la transformación del latifundio tradicional en hacienda capitalista, $y$ al mismo tiempo, apaciguar los conflictos campesinos que venían desde los años 20. En este sentido, se ha dicho, la ley fue exitosa, pese a que, de un lado, motivó la expulsión de arrendatarios, aparceros y colonos en zonas de intensos conflictos (Cundinamarca y Tolima) y de otro, contribuyó a la legalización de las subdivisiones de ciertos dominios que venían desde tiempo atrás en tal proceso ${ }^{2}$.

En el campo laboral fue importante la intervención del gobiemo. Entre 1936 y 1938 se expidieron algunas leyes que versaron sobre los siguientes asuntos: constitución de patrimonios familiares inembargables; inembargabilidad de las 4/5 partes del salario; construcción de casas y granjas para obreros y empleados; descanso remunerado el 10. de mayo; protección a la maternidad y sobre congresos sindicales.

Si bien el gobiemo no se preocupó en especial por reformar la legislación social ${ }^{43}$ fomentó en cambio la sindicalización y actuó como árbitro en los conflictos obrero-patronales, obligando al patrono a negociar, y respaldando en muchos casos las peticiones de los trabajadores. Esta política, encaminada en general a incrementar el poder de negociación de los trabajadores, contribuyó a captar por parte del gobierno el apoyo de las masas y de los sindicatos. 


\section{Revolución en Marcha e Industrialización}

Enrelación con lapolítica económica, algunos historiadores han cuestionado tanto los planteamientos que le otorgan a dicha política el objetivo central de la industrialización, como los que afirman que elavance industrial del período se debió ante todo a la eficacia de tal política, es decir, han cuestionado la determinación industrialista de la Revolución en Marcha. Como se recordará, estos planteamientos parten de la afirmación de que con López ascendió una burguesía industrial al poder, e impuso su proyecto nacional de industrialización. Parecía entonces, como lo observa Marco Palacios, que la burguesía industrial fuera una facción de clase independiente y antagónica de los latifundistas, que buscaba expresión política en el liberalismo más progresista: el de la Revolución en Marcha. El mismo autor subraya que ese no fue el caso de los grandes industriales antioqueños, de los cuales, una buena parte eran conservadores y antiliberales; ni tampoco de los industriales que, sin distingo de partido presionaron contra la legislación sindical y laboral, y combatieron la reforma tributaria que puso a la industria a pagar más impuestos directos que los otros sectores económicos. Más que una burguesía industrial en el sentido clásico -dice el autor citado- "Lo que emerge de la redefinición estructural de los treinta es un grupo de empresarios industriales, vinculados a las capas agroexportadorase importadoras y con la cual mantiene desacuerdos transitorios pero no antagonismos políticos ni económicos"144.

Tampoco el desarrollo industrial fue el resultado de la política estatal. Esta solo en parte estuvo vinculada a dicho desarrollo, Ocampo y Montenegro han demostrado que la gran expansión industrial de los años treinta estuvo asociada a la prolongación de los procesos de transformación de la economía motivados por la expansión cafetera que se inició en 1910; al comportamiento relativamente favorable del sector exporador y a un cambio radical en la composición de las importaciones, lo cual permitió la expansión de la capacidad productiva de las industrias; al mercado que ya se había creado en las décadas anteriores; a los cambios en los patrones de consumo generados por la urbanización y a la política proteccionista. En cuanto a esta última los autores observan que tuvo un efecto importante en los primeros años de la década del treinta, antes de la devaluación de 1932-1935 que erosionó el efecto protector de las reformas arancelarias de 1931; de ahí en adelante, o sea para la segunda mitad de los años treinta, la política arancelaria no tuvo efecto protector, excepto en el caso de los alimentos; empero el gobierno comenzó a utilizar el control directo a las importaciones como un instrumento protector, que tuvo un efecto de reorientación de la demanda hacia la producción internats.

Por su parte, Palacios también subraya el papel indirecto y débil del Estado en la industrialización de los años 30. Ello significa que el Estado "no invirtió directamente, ni orientó su política para que el país se industrializara en tanto que meta prioritaria específica, aunque la retórica industrialista se desparrama por Memorias, mensajes y discursos desde la primera postguerra"46.

Con base en los planteamientos desarrollados hasta aquí, resultarían entonces inexactas aquellas concepciones que interpretan la Revolución en Marcha como "revolución democrático-burguesa", o como "revolución industrial", con la cual habrian entrado en escena la industrialización, la intervención del Estado, la modemización capitalista de la economía y de la sociedad; es decir, lo que quedaría objetado o en últimas sería la determinación unilateral del punto de vista "industrialista" en la interpretación de la Revolución en Marcha, de un lado, y del otro, la concepción de la Revolución en Marcha exactamente como una revolución, pues, como se observó, dicho movimiento no se proponía ni produjo un cambio sustancial en el ordenamiento de las relaciones sociales y económicas; lo que hizo fue contribuir en parte al avance de la modernización capitalista que ya venía desde tiempo atrás; en esto, no era ni revolución democráticoburguesa, ni revolución industrial. En aquellas apreciaciones sobrevalorativas de la Revolución en Marcha habría que ver mas bien la proyección de una ideología del presente.

Empero, las consideraciones anteriprmente efectuadas plantean una aparente contradicción: de una parte, hemos afirmado que durante la crisis de los años treinta se incrementó la intervención del Estado y que ésta recibió un cierto impulso con la Revolución en Marcha; de otra parte, 
hemos planteado al mismo tiempo que dicha intervención tuvo poco que ver con la expansión industrial bajo aquella "revolución". Se trata ciertamente de una aparente contradicción: existe en geheral un reconocimiento acerca de la relativa eficacia del Estado para afrontar la crisis a partir de 1931; se constata así mismo que el Estado puso en juego un conjunto de medidas que se convirticron en mecanismos intervencionistas del Estado. De ahí entonces la aseveración de que surgía de la crisis un Estado con mejores instrumentos de intervención. El impulso que la intervención recibió con la Revolución en Marcha consistía, como atrás se dijo, en la constitución de la base fiscal apropiada al Estado intervencionista; en el otorgamiento de la "estructura jurídica" de los fundamentos legales (constitucionales) para el ejercicio de la intervención; y en el procurar la intervención en campos como el laboral, el agrario y el educativo. Esto era lo que como novedad se agregaba a los medios de intervención previamente adquiridos por el Estado. Ahora bien, si se mira en conjunto la intervención, esta continuaba realizándose, principalmente, a través de las obras públicas, con el cambio ya anotado de la insistencia en las carreteras como infraestructura principal para las articulaciones de mercado (tendencia a la rearticulación y expansión del mercado nacional con fundamento en la red de carreteras); en el manejo de la política monetaria y financiera, del crédito, del control de cambios, del arancel aduanero, de las relaciones comcrciales, de control de importaciones, etc.; en los asuntos laborales y en la cuestión agraria; finalmente, el Estado generaba efectos para la economía por medio de la política fiscal y del gasto público. Lo que pone de manifiesto aquella aparente contradicción, no es la denegación de la intervención estatal, sino el hecho de que el Estado no orientaba su acción directa y prioritariamente al objetivo industrializador, "como proyecto nacional" aunque de dicha acción se derivaran ciertamente efectos estimulantes para el desarrollo industrial. En este sentido, la intervención durante la Revolución en Marcha, y en general durante la República Liberal, establece una línea de continuidad, con la República Conservadora de las primeras décadas del siglo, en cuanto a su función general de contribuír a crear condiciones para el desarrollo capitalista del país; dicho desarrollo, por supuesto, es el que radica en el sector privado de la economía, en función del cual en su conjunto, se planteaba y se ejercía la intervención estatal. Naturalmente que surgen diferencias entre los dos períodos, en cuanto a la amplitud, instrumentos e intensidad de la intervención, y, desde luego, en cuanto al tratamiento de la cuestión social, frente a la cual la Revolución en Marcha asumió un comportamiento de avanzada.

\section{NOTAS}

1 TIRADO, Mejía, Alvaro. Aspectos Políticos del Primer Gobierno de Alfonso López Pumarejo 1934-38 , Procultura S. A. Instituto Colombiano de Cultura. Bogotá, 1981, p. XI.

2. Por supuesto que la intervención de la ideología y del partido político en la visión del pasado es mucho más compleja. Si aquí solamente hemos señalado la tendencia a la sobrevaloración y la idealización del pasado, puede presentarse, igualmente, la inclinación a la subvaloración, a la crítica negativa del pasado, tal como ha sucedido en algunos momentos de ruptura o de cambio revolucionario. En este caso, los agentes del cambio, para legitimar y justificar la empresa revolucionaria del presente, elaboran una visión negativa del pasado, así lo hicieron, valga el ejemplo, los historiadores liberales de mediados del siglo XIX, quienes acompañaron la transfomación de la herencia colonial con una crítica despiadada del pasado colonial (a propósito véase B. Tovar Z.: La Colonia en la Historiografía Colombiana. Ed. La Carreta, Bogotá, 1984). Más recientemente es perceptible también este tipo de enfoque en algunos historiadores liberales, quienes para relievar los gobiemos de la República liberal, tienden a proporcionar una visión poco anuente con el período anterior conocido como la República Conservadora.

3. "En sintesis, expresa Gerardo Molina, la etapa que López quiso acaudillar fué la de la liquidación de la colonia y la del viraje hacia la Revolución Industrial, para lo cual se apoyb en la burguesía progresista y en las zonas populares de mayor conciencia". Gerardo Molina, Las Ideas liberales en Colombia 1915-1934. Ed. Tercer Mundo, Bogotá 1974, Tomo I, p. 280 (del mismo autor véase también el Tomo III, p. 23 y ss.).

4. Describiendo las reformas de la Revolución en Marcha, Francisco Posada concluye "Estas fueron las primeras bases de la revolución democrático-burguesa. El pueblo y las organizaciones progresistas respaldaban al Presidente López. Pero sin la aplicación de otras medidas, absolutamente indispensables para llevar adelante dicha revolución, esas bases podían que dar sin edificio, como efectivamente quedaron" Francisco Posada: Colombia: Violencia y Subdesarrollo, Bogotá 1968. p. 98 Refiriéndose al equipo que acompañaba a López el mismo autor expresa que procedía de la joven burguesía industrial, de la pequeña burguesía y de la nueva intelectualidad (Ibidem, p. 98). 
5. Para algunos autores, las situaciones son un poco diferentes: Se trata antes de los años treinta, de un bloque dominante, en el cual "el sector exportador tiene el predominio conservando el sector agrario una amplia in. fluencia en el Eslado. Estos dos sectores constituyeron una alianza oligárquica. Por su parte, los industriales, conformados a la sombra de las divisas producidas por las exportaciones solo podían aspirar a una posición de subordinación en esta alianza". Rocío Londoño y Fabio Velásquez: Proceso económico y jurídico-político de Colombia. Ediciones Camilo, Bogotá 1974, p. 118 (lo destacado es nuestro). En este planteamiento los autores siguen a Daniel Pecaut, quien expresa que durante la fase de desarrollo "hacia afuera" el sector exportador ocupa una posición dominante, lo cual "no significa necesariamente que este sector controle por completo al Estado, puesto que los sectores agrarios que producen para el mercado intemo pueden conservar una amplia influencia sobre el Estado". Daniel Pecaut: Política y Sindicalismo en Colombia. Ed. La Carreta, Bogotá 1973, p. 24.

6. De un modo un poco diferente al expuesto, Jesús $A$. Bejarano, sugiere que con el viraje de los años 30 se abría la oportunidad de extender la intervención del Estado de la esfera del comercio exterior hacia la incentivación del desarrollo interno. "El regimen político anteriot -expresa- corno se comprende fácilmente, era incapaz de utilizar el Estado para crear condiciones adecuadas al desarrollo industrial, y ello era así tanto por el carácter rentístico de la estructura agraria como por la vocación exportadora de la economía, que hacía innecesaria toda intervención como no fuera del comercio exterior. Era evidente entonces que la oportunidad del viraje político se recibiese ante todo como la oportunidad de inclinar al Estado en favor del desarrollo económico. A esta idea debieron apuntarse tanto la burguesía manufacturera y comercial como aquellos propietarios que veían en el trabajo asalariado y en la expansión del mercado interior el camino para una más acelerada inversión de capitales. Iban a darse así -agrega- las condiciones tanto económicas como políticas para el desarrollo industrial, que la crisis del treinta se encargaría sólo de acelerar, pero no de producir". Jesús Antonio Bejarano. El Regimen Agrario de la Economía exporiadora a la economía industrial. Ed. La Carreta. Bogotá 1979, pp. 234-235.

7. "De todas maneras, solamente con el ascenso de López Pumarejo al poder y con él los grupos industriales, se dará cabida a una vigorosa política de industrialización". Rocío Londoño y Fabio Velásquez, op cit . pp. 134,135.

8 MEDINA, Medófilo: "Historia del Parlido Comunisla de Colombia" . CEIS, Bogolá 1980, Tómo I, pp.287 - 288.

9 MOLINA, Gerardo. Op, cit. Tomo III. pp.103-104. Véase también Gabriel Poveda Ramos. "Políicas Económicas, Desarrollo Industrial y Tecnológico en Colombia, 1925 - 1975". Colciencias, Bogotá, 1976.

10 GALINDO, Alberto. "La República Liberal", en El Liberalismo en el Gobiemo, sus hombres, sus ideas, su obra, 1930 - 1946. Bogotá. Tomo I. p.83.

II Ibidem. p. 84.

12 Ibidem. pp. 75 y 83.

13 Para Gustavo Humberto Rodríguez, quien proporciona una visión poco entusiasta de los años veinte, el intervencionismo de Estado habría comenzado un poco antes, exactamente con el gobiemo de Olaya Herrera: él fue -expresa- quien "rompió las amarras del feudalismo colonial que venía imperando a lo largo de nuestra evolución republicana. Fue êl quien abrió las puertas del sistema capitalista en Colombia. Lo hizo sobre tres bases esenciales: introduciendo el intervencionismo estatal como regulador de la economía, el proteccionismo agroindustrial como elemento básico del desarrollo material y la promoción de las reformas sociales que le garantizaron la seguridad al hambre colombiano "y agrega" Olaya fue, pues el gestor del intervencionismo estatal en Colombia. Olaya fue el iniciador de la seguridad social colombiana... con sus grandes dotes de administrador hizo posible la "revolución en marcha" que un régimen de partido inició en el custrienio siguiente". Gustavo Humberto Rodríguez, Olaya Herrera, Política, estadista y Caudillo. Banco de la República, Bogota 1981, pp. 219, 220 y 223.

14 Véase Jesús Antonio Bejarano. Op. cit. p. 70 y ss.

15 Véase William Paul McGreevey. "Historia Económica de Colombia 1845-1930" . Ed. Tercer Mundo, Bogota 1975, pp. 251 y ss.

16 Quien mejor formulo la crítica al régimen fiscal fue Esteban Jaramillo, en su libro La Reforma Tributaris en Colombia. Pablicaciones del Banco de la República, archivo de la Economía Nacional, Bogotá, 1956. La argumentación de Jaramillo estaba orientada a sustentar la reforma tributaria de 1918 , que introdujo el impuesto a la renta.

17 Para una visión más detallada de la intervención del Estado hasta los comienzos de ls Repóblica Liberal, véase Bernardo Tovar Zambrano. "La Intervención económica del eslado en Colombia 1914-1936". Banco Popular, Bogotá 1984.

18 Véase B. Tovar Z "Modemización y Desarrollo desigual de la Intervención Estatal 1914 - 1946" en Pasado y Presente de la Violencia en Colombia. CEREC, 1986.

19 Mesa Darío. "La Vida Polftica después de Panamá" en Manual de Historia de Colombia. Colcultura, Bogotá, 1983. Tomo III, p. 93 y ss.

20 López, Hugo. "La inflación en Colombia en la década de los veinte" en Cuadernos Colombianos No. 5, Bogotá 1975, pp. 110-112.

21 Presidencia de la República. Discursos y mensajes de posesión presidencial. Imprenta Nacional. Bogotá 1981, Vol. VII, tomo I, p. 165.

22 Molina, Gerardo. Op.cil. Tomo I, p. 150. También Indalecio Liévano Aguirre. Rafael Núñez. Ed. Librería Siglo XX. Bogotá 1946.

23 Núñez, Rafael. Diccionario Polático. Biblioleca de Autores Colombianos, Bogotá, 1952. p. 160.

24 Uribe, Uribe, Rafael. "Socialismo de Estado" en Otras Selectas, Colección "Pensadores Políticos Colombianos, Cámara de Representantes, Bogotá 1979, Tomo I, pp. 3475: también Darío Múnera Arango. El Derecho Económico ensayo sobre la aparición de un nuevo dominio jurídico. Biblioteca de Autores contemporáneos, Bogota 1963. pp. 217 y 218.

25 Uribe, Vargas, Diego. Las constituciones de Colombia (Historia - crítica y textos). Ediciones Cultura Hispanica, Madrid 1977. Tomo II, Pp. 983, 984, 995, 1005 y 1006.

26 Jaramillo Uribe, Jaime. El pensamiento celombiano en el 
Siglo XIX. Ed. Temis, Bogotá 1964, p. 343 y ss.

27 Caro, Miguel Antonio. Escrilos sobre cuestiones económicas. Banco de la República. Bogotá 1956. p. 81.

28 Uribe, Uribe, Rafael. Op.cit , pp. 29 y 30.

29 Ibidem. p. 33.

30 Vélez, Humberto. "Rafael Reyes o el Primer Experimento burgués en Colombia" en Historia y Espacio, Revista de Estudios Históricos Regionales. U. del Valle, No. 8, Cali. Mayo-Julio de 1983. p. 26

31 Revista Nacional de Agricultura Nos. 11 - 12. Junio de 1911, pp. $27-49$.

32 Primer Congreso de Camaras de Comercio de Colom. bia. Estudios y Conclusiones. Imprenta Nacional, Bogotá 1917. Primer Congreso de Mejoras Nacionales. Imprenta Nacional, Bogotá, 1917.

33 Jaramillo, Esteban. Op. cit. p. 23

34 Jaramillo, Uribe, Jaime. Antología del Pensamiento Polático Colombiano. Banco de la República. Bogotá, 1970. Tomo II.

35 Para una visión más detallada véase B. Tovar $\mathrm{Z}$. La intervención económica... p. 210 y ss.

36 Citado por Alfonso Patiño Rosselli. La prosperidad a debe y la gran crisis, 1925 - 1935. Banco de la República. Bogotá 1981, pp. 593-594.
37 Anales de la Cámara de Representantes. Na 71. Viemes 11 de octubre de 1935, pp. 875 y 884.

38 Anvario General de Esladística. 1936 - 1940.

39 Ocampo, José Antonio y Santiago Montenegro. Crisis Mundial, Prolección e Industrialización, ensayos de historia económica colombiana. CBREC, Bogotí, 1984. p. 310 .

40 Tirado Mejía, Alvaro y Magdala Velísquez, La Reforma Constitucional de 1936. Oveja Negra, Bogotá 1982, pp. $137 \cdot 143$.

41 Molina, Gerardo. Op. cit. p. Tomo III, p. 76

42 Fajardo, Dario. Haciendas, campesinos y políticas agrarias en Colombia, 1920 - 1980. Ed. Oveja Negra, Bogotá, pp. 52 - 64.

43 Molina, Gerardo. Op. cif. p. 90. Algunos, sin embargo, afirman que las reformas laborales de la revolución fueron "muchss". Véase por ejemplo el fascículo de Benjamín Ardila Duarte "Grandes reformas liberales" No. 15, Colección Historia de Colombia. Ed. Oveja Negra. Bogotá, 1986.

44 Palacios, Marco. El café en Colombia 1850-1970" Una historia económica, social y política. Bl Ancora Editores, Bogotá, 1983, p. 506. 